\title{
Thinking About Events: A Pragmatist Account of the Objects of Episodic Hypothetical Thought
}

\author{
André Sant'Anna ${ }^{1}$ id . Kourken Michaelian ${ }^{1}$
}

(C) Springer Science+Business Media B.V., part of Springer Nature 2018

\begin{abstract}
The debate over the objects of episodic memory has for some time been stalled, with few alternatives to familiar forms of direct and indirect realism being advanced. This paper moves the debate forward by building on insights from the recent psychological literature on memory as a form of episodic hypothetical thought (or mental time travel) and the recent philosophical literature on relationalist and representationalist approaches to perception. The former suggests that an adequate account of the objects of episodic memory will have to be a special case of an account of the objects of episodic hypothetical thought more generally. The latter suggests that an adequate account of the objects of episodic hypothetical thought will have to combine features of direct realism and representationalism. We develop a novel pragmatist-inspired account of the objects of episodic hypothetical thought that has the requisite features.
\end{abstract}

\section{From the Objects of Memory to the Objects of Episodic Hypothetical Thought}

When a subject remembers an event, to what is he related, in the first instance? What, in other words, are the direct objects of episodic memory? This is the traditional

André Sant'Anna

rosolemandre@gmail.com

1 Department of Philosophy, University of Otago, PO Box 56, Dunedin, 9054, New Zealand 
question of the objects of episodic memory. ${ }^{1}$ Following Reid, direct realists have argued that the direct objects of memory are past events themselves. Following Locke and Hume, indirect realists have argued that the direct objects of memory are not events but rather representations of events, claiming that it is only in virtue of his (direct) relation to a representation that a remembering subject is (indirectly) related to an event. Contemporary discussions of the objects of memory continue to unfold largely within this early modern framework, but the framework predates the empirical psychology of memory, and we suggest that it may be time to move beyond it. We suggest, in particular, that it may be time to replace the traditional question of the objects of episodic memory with a question that takes contemporary psychological thinking about memory into account: the question of the objects of episodic hypothetical thought.

Adopting De Brigard (2014a) terminology, we use "episodic hypothetical thought" as a blanket term referring not only to episodic memory (roughly, the capacity to remember events that occurred in the personal past) but also to episodic future thought (the capacity to imagine events that might occur in the personal future) and episodic counterfactual thought (the capacity to imagine events that might have but did not occur in the personal past). ${ }^{2}$ In philosophy, it has generally been assumed that there is no need for an adequate positive account of episodic memory to refer to these other forms of episodic hypothetical thought - that, if they figure in an account of memory at all, they will do so merely negatively, as forms of imagination from which memory must be distinguished. In psychology, in contrast, it is increasingly taken for granted that episodic memory can be adequately understood only if it is seen as one instance among others of a more general capacity for simulating possible episodes. On this view, episodic memory overlaps heavily with other forms of episodic hypothetical thought — also known as "mental time travel" — at every level from the neural to the phenomenological. This is not the place to summarize the evidence in favour of the psychological approach (see Michaelian 2016c for a review), and we will simply take for granted the consensus view that the more general category of episodic hypothetical thought is prior to the more specific category of episodic memory. This view suggests that the traditional question of the objects of episodic memory should be replaced with a new question: What are the direct objects of episodic hypothetical thought? When a subject thinks about a possible event, to what is he related, in the first instance?

In what follows, we defend a specific answer to this question. Our argument unfolds in two stages, with the first stage being primarily negative in character. We build in this stage on two distinct literatures. The psychological literature on episodic hypothetical thought, on the one hand, provides new insights into the relationship between episodic memory and other forms of episodic hypothetical thought. The

\footnotetext{
${ }^{1}$ The term "episodic memory" originates in psychology (Tulving 1985a). Philosophers have historically referred to episodic memory using a variety of different terms but are increasingly adopting the psychological terminology (Perrin and Rousset 2014).

${ }^{2}$ In Section 4, we introduce a fourth category of episodic hypothetical thought: future-oriented episodic counterfactual thought.
} 
philosophical literature on the objects of perception, on the other hand, which is considerably more advanced than the literature on the objects of memory, points to the need for and possibility of alternatives to traditional forms of direct and indirect realism. Building on these two literatures, we arrive at two conclusions. In Section 2, we show that, when the traditional question is replaced with the new question, as research on episodic hypothetical thought suggests it ought to be, a previously overlooked problem for direct realism comes to light: direct realists have usually been disjunctivists, but it turns out that direct realism leads to a form of disjunctivism far more extreme than has hitherto been appreciated. Indeed, the form of disjunctivism in question is unacceptably extreme, and our first conclusion is thus that direct realism should no longer be seen as a viable option. In Section 3, however, we show that considerations originally adduced by philosophers of perception demonstrate, when applied to the domain of episodic hypothetical thought, that indirect realism is equally problematic: episodic hypothetical thoughts turn out to be "silent" in the sense that they do not establish their own satisfaction conditions. This, in turn, undermines indirect realism, and our second conclusion is thus that indirect realism should likewise no longer be seen as a viable option.

Overall, the first stage of the argument suggests that an adequate account of the objects of episodic hypothetical thought will preserve the desirable features of direct and indirect realism while eliminating those that render them unviable. The second stage of the argument is positive in character, aiming to develop an account of this sort. We build in this stage on a third, older literature, finding, in Section 4, the starting points for an alternative to direct and indirect realism in Peircean pragmatism and developing these into a detailed pragmatist account of the objects of episodic hypothetical thought. Given its unfamiliar character, the pragmatist account is bound to be controversial, and, while we cannot hope to respond here to all objections that the account is likely to encounter, we do, in Section 5, respond to what we take to be the most pressing objection to the account, arguing that it can, initial appearances to the contrary notwithstanding, successfully accommodate the role of autonoetic consciousness in episodic hypothetical thought. Thus, while we may not succeed in persuading readers antecedently sceptical of pragmatism that the pragmatist account is the way to go, our third and final conclusion is nevertheless that it represents a promising avenue for future research in this area.

We note in advance that the argument of the paper is somewhat complex, as it both takes on an unfamiliar question (the question of the objects of episodic hypothetical thought) and approaches that question via an unorthodox theoretical framework (pragmatism). We ask our readers to bear with us. The pragmatist account may be unorthodox, but its ability to avoid the problems that undermine orthodox direct and indirect realist accounts speaks in its favour. Moreover, even readers who are ultimately unpersuaded by the pragmatist account (the second stage of our argument) may be persuaded by the claim that direct and indirect realism fail to provide adequate accounts of the objects of episodic hypothetical thought (the first stage of our argument). As this claim does not itself rest on pragmatist assumptions, it is, we believe, incumbent upon opponents of pragmatism to show how the objects of episodic hypothetical thought can be accounted for within a nonpragmatist theoretical framework. 


\section{Direct Realism and Extreme Disjunctivism}

This section sets out the first part of the negative stage of our argument. After motivating direct realism (Section 2.1), we describe two problems for the view (Section 2.2). The first, the co-reality problem, is a generalization of the co-temporality problem familiar from discussions elsewhere in the philosophy of memory. The second, the problem of confabulation and misremembering, is a counterpart to the problem of hallucination and illusion familiar from discussions in the philosophy of perception. Our discussion of these problems will show that, once episodic memory has been situated as a form of episodic hypothetical thought, it becomes clear that direct realism implies an unacceptably extreme form of disjunctivism.

\subsection{Motivating Direct Realism}

Just as direct and indirect realism about the objects of perception can be seen as particular ways of spelling out basic relationalist and representationalist accounts of the objects of perception, direct and indirect realism about the objects of memory can be seen as ways of spelling out basic relationalist and representationalist accounts of the objects of memory. According to relationalism, memory is fundamentally relational, in the sense that it necessarily involves a relation between the remembering subject and the remembered event. For the relationalist, states of remembering involve remembered events as constituents, which implies that, if one is not appropriately related to an event, one is not literally remembering. According to representationalism, memory is fundamentally representational, in the sense that it does not necessarily involve a relation between the remembering subject and the remembered object. For the representationalist, states of remembering do not involve remembered events as constituents; instead, they involve internal representations, which implies that one might literally remember despite not being appropriately related to an event. Relationalism comes in a variety of forms, and it will be crucial to our argument here that forms of relationalism other than direct realism are available, as the pragmatist account can be seen as an unusual form of relationalism. Direct realism - which can be defined as the result of combining generic relationalism with the naive realist assumption that the event to which the remembering subject is related is an ordinary, concrete, particular event - is, however, the only form of relationalism that has so far received sustained attention, and it therefore provides the starting point for our discussion.

One reason often offered in favour of direct realism is that, unless the indirect realist can identify criteria that enable the subject to distinguish genuine from merely apparent memory representations, indirect realism may lead to scepticism about memory knowledge (Bernecker 2008). Some indirect realists have argued that such criteria can in fact be identified (Michaelian 2016c), but these arguments do not respond to what what is often considered to be the most intuitively powerful reason in favour of direct realism, namely, that it aligns with the phenomenological directness of remembering. Its phenomenological plausibility has meant that, while indirect realism has also found many adherents, direct realism has remained a popular view. 
There are significant disagreements among different varieties of direct realism, but all direct realists are in agreement on the naive realist assumption identified above. In an oft-quoted formulation, Laird (1920), for example, maintains that "memory does not mean the existence of present representatives of past things. It is the mind's awareness of past things themselves". More recently, Bernecker emphasizes that, "on the [direct] realist view, what one is directly aware of in memory is the past event in propria persona, and not some representation of it" (Bernecker 2008, 68). Debus is similarly explicit, arguing that "[t]he [recollectively] remembered object or event itself is a part of the [recollective] memory" (Debus 2008, 405). There is no hint in any of these formulations that the objects of memory are anything other than ordinary, concrete, particular past events.

\subsection{Extreme Disjunctivism}

Though it remains popular, direct realism faces serious problems. Here, we argue that two such problems ultimately undermine the appeal of direct realism.

\subsubsection{From the Co-temporality Problem to the Co-reality Problem}

The first problem arises because the mental state of remembering and the event that is remembered are located at different points in time, making it difficult to see how the latter might be the direct object of the former. Direct realism about perception may face a version of this "co-temporality problem" (as Bernecker 2008 refers to it) as well, since the process of perceiving takes time to unfold (Russell 1992). But, whereas the object perceived and the state of perceiving often at least overlap in time, the event remembered and the state of remembering may be separated by periods of many years, and the problem is arguably more urgent for direct realism about memory.

Responding to the co-temporality problem, Debus (2008) argues that direct realists can allow that the past event can serve as the direct object of the present mental state as long as they assume that the latter stands in the right sort of causal relationship to the former - in other words, as long as direct realism is combined with the causal theory of memory (Martin and Deutscher 1966). Given, however, that — as Debus herself emphasizes - what it is for an event to be the direct object of a mental state is for it to be a constituent of that state, it remains difficult to see how an event located in the past might be the direct object of a state of remembering located in the present. Bernecker (2008), who, like Debus, combines direct realism with the causal theory, argues that direct realists can overcome this difficulty if they reject presentism, the view that events exist only at the times at which they occur, in favour of eternalism, the view that events do not cease to exist once they have occurred (Price 1936). If past events continue to exist once they have occurred, they are in principle available to stand in constitutive relations with present mental states, and adopting eternalism might thus in principle allow the direct realist to avoid the co-temporality problem.

Eternalism is an intuitively implausible view. Some may already be convinced of eternalism for independent reasons. To them, the eternalist solution to the cotemporality problem comes at no extra metaphysical cost. Others, of course, are not 
so convinced. To some of these, the price of the solution may seem to be too high. To others, the price may seem to be worth paying, but we argue in the remainder of this section that, if direct realism is understood as an answer not just to the question of the objects of episodic memory but also to the question of the objects of episodic hypothetical thought, the cost of the solution goes up dramatically. It eventually turns out, moreover, to be inapplicable to forms of episodic hypothetical thought other than episodic memory, rendering it unavailable even to those convinced of eternalism for independent reasons.

Direct realism about the objects of episodic hypothetical thought as a whole would be an unusual view, but it is not difficult to motivate. The most intuitively powerful reason in favour of direct realism about the objects of episodic memory, as we have seen, is the phenomenological directness of remembering: when one remembers an episode, one (in most cases) feels as if one is attending to the episode itself, not to an internal representation of the episode. Similarly, when one imagines a future or counterfactual episode, one (in most cases) feels as if one is attending to the episode itself, not to an internal representation of the episode. Thus forms of episodic hypothetical thought other than episodic memory share the phenomenological directness of episodic memory, and we might appeal to this shared phenomenological directness to motivate a direct realist account of the objects of episodic hypothetical thought as a whole. According to direct realism about episodic hypothetical thought, the direct objects of episodic hypothetical thought would be possible events - actual past events, in the case of episodic memory, possible future events, in the case of episodic future thought, and merely possible past events, in the case of episodic counterfactual thought.

Despite its phenomenological plausibility, this account immediately encounters serious stumbling-blocks. Because direct realism about episodic hypothetical thought holds that the direct objects of episodic future thought are future events, it faces a version of the co-temporality problem significantly more severe than that faced by direct realism about episodic memory. What we might think of as the "extended cotemporality problem" is the problem of explaining how events that were experienced by the subject in the past, as well as events that merely might be experienced by the subject in the future, can be constituents of his present mental states. Building on the eternalist solution, the direct realist might argue that events do not exist only at the times at which they occur, not only in the sense that an event does not cease to exist once it has occurred but also in the sense that it does not begin to exist only when it occurs. If events are (so to speak) eternal in both directions, both past and future events are in principle available to stand in constitutive relations with present mental states, and adopting this extended form of eternalism might thus in principle allow the direct realist to avoid the extended co-temporality problem.

Extended eternalism does not, however, provide a full explanation of how possible events can be the direct objects of episodic hypothetical thought. Because direct realism about episodic hypothetical thought holds that the direct objects of episodic counterfactual thought are counterfactual events, it faces a problem yet more severe than the extended co-temporality problem. What we might think of as the "co-reality problem" is the problem of explaining how events that merely could have been experienced by the subject in the past might be constituents of his present mental states. In 
order to avoid the co-reality problem, the direct realist might argue that events exist regardless not only of when they occur but also of whether they occur at all. This solution, it should be emphasized, comes at a much higher metaphysical price - a price on a par with that of modal realism - than the eternalist solutions introduced in response to the co-temporality problem and the extended co-temporality problem.

Even if we are in principle willing to pay the price, moreover, the solution is subject to a fatal difficulty. The original co-temporality problem arose because it was unclear how an event might serve as the direct object of a mental state despite not existing at the same time as the mental state. Eternalism provides a solution to this problem, but it does so, as we have seen, only given the further assumption that episodic memory involves an appropriate causal relationship to the subject's experience of the past event. The variants of eternalism considered here fail to provide a solution to the extended co-temporality problem or to the co-reality problem simply because, in forms of episodic hypothetical thought other than episodic memory, the subject has not experienced the relevant events and therefore stands in no suitable causal relationship to them. In principle, merely possible events might be available to stand in constitutive relationships with thoughts about them; in practice, it is entirely unclear what mechanism might enable them to do so.

The prospects for applying direct realism to episodic future thought and episodic counterfactual thought thus appear dim. Indeed, Debus (2014; cf. Perrin 2016) has explicitly argued that there is a difference in kind between episodic memory and episodic future thought, on the ground that, in episodic memory, the subject stands in an experiential (ultimately, a causal) relation to a particular event, whereas, in episodic future thought, the subject does not and could not stand in an experiential (causal) relation to a particular event. She thus in effect adopts a form of disjunctivism, with episodic memory as one disjunct and episodic future thought as the other. A subject is, of course, no more capable of standing in an experiential relation to a counterfactual event than he is of standing in an experiential relation to a future event; adopting a disjunctivist view of episodic memory and episodic future thought will thus naturally lead us to adopt disjunctivism about episodic hypothetical thought as a whole, with episodic memory as one disjunct and episodic future thought and episodic counterfactual thought as the other.

\subsubsection{The Problem of Confabulation and Misremembering}

Disjunctivism about episodic hypothetical thought is distinct from traditional disjunctivism, according to which there is a difference in kind, within the category of episodic memory, between successful and unsuccessful remembering. Traditional disjunctivism is imposed on the direct realist about memory by the need to respond to a second problem, a problem posed by confabulation and misremembering analogous to the problem posed by hallucination and illusion the need to respond to which imposes a similar form of disjunctivism on the direct realist about perception. ${ }^{3}$

\footnotetext{
${ }^{3}$ See Robins (2016) on the relationship between the confabulation/misremembering distinction and the hallucination/illusion distinction.
} 
Disregarding unnecessary technical details, the argument runs as follows. (1) The mental states at issue in cases in which we remember events that did not occur, i.e., cases of confabulation (or "memory hallucination"), or in which we remember events that did not occur as we remember them occurring, i.e., cases of misremembering (or "memory illusion"), cannot have past events as their objects. (2) The mental states at issue in cases of successful remembering and those at issue in cases of unsuccessful remembering, including confabulation and misremembering, have objects of the same kind. Therefore, (3) the mental states at issue in cases of successful remembering do not have past events as their objects. While this is not directly entailed by 3 , the representationalist invites us to draw the further conclusion that (4) the direct objects of memory, both in cases of successful remembering and in cases of unsuccessful remembering, are internal representations. Of the steps of this argument, 1 is the least controversial. In order to avoid having to accept 3 - and hence potentially being led to accept 4 - direct realists have therefore rejected 2 , the claim that the objects of memory must be of the same kind in successful and unsuccessful remembering. Bernecker, for example, maintains that "[w]hat we are aware of in genuine memory is different from what we are aware of in ostensible memory. In genuine memory we are aware of past events. In ostensible memory, if we are aware of anything ... we are aware of mental entities" (Bernecker 2008, 74).

Putting traditional disjunctivism together with disjunctivism about episodic hypothetical thought, it becomes clear that direct realism in fact leads to a disjunctivism considerably more extreme than has generally been recognized, with successful memory as one disjunct, and future thought, counterfactual thought, and confabulation and misremembering as the other. This extreme disjunctivism might seem to be acceptable as long as we take ourselves to be entitled to single successful remembering out as having a special status. But a look at, first, the ordinariness of confabulation and misremembering and, second, the centrality to our mental lives of forms of episodic hypothetical thought other than episodic memory suggests that we are not so entitled. Indeed, it suggests that direct realism in fact leads to a disjunctivism so extreme as to be clearly unacceptable, a disjunctivism according to which the size of the "successful memory" disjunct at best is dwarfed by that of the "other" disjunct and at worst may be outright empty.

Setting forms of episodic hypothetical thought other than memory aside for the moment, consider confabulation and misremembering. It is important to note at the outset that, by positing a difference in kind between successful memory, on the one hand, and confabulation and misremembering, on the other hand, disjunctivism makes what intuitively seems to be a unified mental phenomenon into something fundamentally disunified. Disjunctivism should therefore be seen not as a position which is intrinsically attractive but rather as a position to which the direct realist is compelled to retreat in order to save his view. It is thus unsurprising that defences of disjunctivism often implicitly assume that successful memory is the norm, i.e., that confabulation and misremembering are exceptions to the rule, as this assumption makes the "successful memory" disjunct seem larger or more central than the "unsuccessful memory" disjunct, thus minimizing the intuitive implausibility of the 
view. The assumption is, however, unjustified. There is no way of estimating the precise frequency of confabulation and misremembering outside the laboratory, but what we have learned about the workings of memory from laboratory studies tells us that they must be very frequent indeed. Loftus and her colleagues, for example, have demonstrated that it is possible to implant memories of entire events that were not experienced by the subject (Loftus 2005). Crucially, no special technology is required to implant such memories. Simply having subjects repeatedly imagine an event is often sufficient to lead them to "remember" it, which suggests that we sometimes unknowingly implant memories in ourselves. Such cases of confabulation may be relatively rare, but cases of misremembering are likely to occur more frequently. Again, no special technology is required to induce subjects to misremember. In the Deese-Roediger-McDermott paradigm, for example, subjects who are simply presented with lists of thematically-related words often end up remembering non-presented but thematically-consistent lure words (Gallo 2010). Analogous conditions occur routinely in non-laboratory settings, suggesting that misremembering is anything but rare.

Confabulation and misremembering occur because memory has a reconstructive, rather than a reproductive, character: rather than being a matter of the preservation of a representation or a relationship established at the time of experience, remembering is, as Bartlett put it in his foundational study (Bartlett 1932), always a matter of creating something anew on the basis both of the subject's past experience and of his present state of mind. The evidence for the reconstructive character of remembering that has accumulated since Bartlett's time is overwhelming, and we will not attempt to summarize it here (see Michaelian 2011 for an overview). Suffice it to say that the evidence makes it clear that, while full-blown confabulation appears to be relatively rare in healthy subjects, misremembering is clearly a widespread and inevitable consequence of the normal functioning of memory. This suggests that the size of the "unsuccessful memory" disjunct is far larger than traditional disjunctivists have taken it to be. Depending on how the argument from confabulation and misremembering is interpreted, in fact, it may even be virtually empty. Research on constructive memory suggests that, because all memories include details not derived from experience of the relevant events, they inevitably depart to some extent from experience and are thus to some extent false (e.g., Conway and Loveday 2015). All memories, in other words, are to some extent mismemories. This goes, for example, even for so-called "flashbulb memories", exceptionally detailed and phenomenologically compelling memories of dramatic events (Newman and Lindsay 2009). Thus, if the argument from confabulation and misremembering is interpreted in such a way that it implies that all mismemories belong in the "unsuccessful memory" disjunct, there may be little or nothing left in the "successful memory" disjunct.

Turning to episodic hypothetical thought, while it is difficult to estimate the relative frequencies with which different forms of episodic hypothetical thought occur, there is every reason to think that episodic future thought occurs quite frequently (D'Argembeau et al. 2011): from an adaptive perspective, it is to be expected that we spend as much time thinking about and planning for the future 
as we do thinking about the past, and quite possibly more. Much of the time that we do spend thinking about the past, moreover, is devoted not to attempting to faithfully reproduce past events but rather to exploring what might have been had things gone differently - that is, to episodic counterfactual thought, rather than to episodic memory (De Brigard 2014a). Occurrences of episodic memory thus may account for a relatively small fraction of occurrences of episodic hypothetical thought.

In fact, research on mental time travel, like research on constructive memory, suggests that direct realism may ultimately be unable to acknowledge any instances at all of successful or genuine memory. The argument from confabulation and misremembering focuses on cases in which memory is at least to some extent inaccurate with respect to past events. But there are also cases in which memory is accurate with respect to past events but which direct realism cannot classify as instances of genuine memory. On views such as Debus's and Bernecker's, we have seen, a past event is able to serve as a constituent of a present state of remembering only because memory involves an appropriate causal relationship between the present state and the past event. In other words, in cases in which no causal relationship obtains, the past event cannot serve as a constituent of the present state, regardless of the accuracy of the apparent memory. In such cases, the present state will, by direct realist standards, fail to qualify as an instance of genuine memory. What mental time travel research seems to imply, however, is that, even in many cases of accurate apparent memory, no causal relationship between the present state and the past event obtains (Michaelian 2016a). The overlap among episodic memory, episodic future thought, and episodic counterfactual thought suggests that episodic memory is a form of episodic imagination. Like other forms of episodic imagination, remembering draws on past experience to simulate a target event. Forms of episodic imagination other than episodic memory, of course, cannot and do not draw on experience of the particular events they target; similarly, episodic memory can but need not draw on experience of the events it targets. In many cases, the subject's experience of a target event does play a role in shaping his memory of the event, and, in such cases, there may be an appropriate causal link between the present memory and the past event. But even in such cases, experience of the target event is typically not alone in shaping the memory - there may be equally strong or even stronger links to one or more other events. And in some cases, experience of the target event plays no role at all in shaping the memory - instead, the memory builds entirely on experience of other events. In such cases, memory involves no causal link whatsoever with the past event. The upshot, again, is that the "successful memory" disjunct may be empty or virtually empty.

This concludes the first part of the negative stage of our argument. To summarize: The form of disjunctivism traditionally thought to follow from direct realism is already unappealing. The extreme form of disjunctivism that in fact follow from direct realism is far less appealing: if extreme disjunctivism is right, genuine memory is, if it occurs at all, not the rule but rather a rare exception. We conclude that, once episodic memory has been situated as a form of episodic hypothetical thought, direct realism no longer appears to be a viable option. 


\section{Representationalism and the Silence of Episodic Hypothetical Thought}

Turning to the traditional alternative to direct realism - indirect realism or representationalism - this section sets out the second part of the negative stage of our argument. Indirect realism would in principle provide a means of avoiding extreme disjunctivism. After reviewing the motivation for representationalism (Section 3.1), however, we show that it, like direct realism, is subject to a previously-overlooked but fatal problem (Section 3.2): just as perceptual states are "silent" in the sense that they do not establish their own satisfaction conditions, so, too, are episodic hypothetical thoughts. This undermines the representationalist approach.

\subsection{Motivating Representationalism}

The most powerful reason in favour of direct realism, we saw above, is the phenomenological directness of remembering. The most powerful reason in favour of representationalism, in contrast, is its capacity to give an account of the objects of memory that avoids both the co-reality problem and the problem of confabulation and misremembering. Representationalism can provide such an account simply because it holds that, when we remember past events, we are directly related not to events themselves but rather to internal representations of events.

We take a mental state to be representational if it presents the world as being a certain way to the subject, i.e., if it has satisfaction conditions. A representational state is accurate if its satisfaction conditions are met by a state of affairs in the world; otherwise it is inaccurate. Taking episodic memories to be representational in this sense straightforwardly allows us to avoid the co-reality problem. According to representationalism, when we engage in episodic hypothetical thought, the direct objects of our mental states are internal representations of events. Because these representations are located in the present, there is no mystery about how they might serve as the direct objects of present mental states: just as the representations involved (on a representationalist account) in perception can represent scenes that are not before the subject's eyes or do not occur at all, the representations involved in episodic hypothetical thought can represent events that occur at other times or that do not occur at all. Taking episodic memories to be representational also allows us to avoid the problem of confabulation and misremembering. Representationalism avoids this problem because it denies that events serve as the direct objects of memory. The difference between successful memory and unsuccessful memory is to be understood in terms of the accuracy of the relevant representations: in cases of misremembering, the satisfaction conditions of the representations are met only to some degree, and, in cases of confabulation, they are not met at all.

Representationalism thus allows us to avoid not only traditional disjunctivism but also extreme disjunctivism. Because it places memory in one category and other forms of episodic hypothetical thought in another, direct realism is bound to treat episodic memory as something exceptional. In contrast, because it says that the direct object of any instance of episodic hypothetical thought — whether episodic memory, 
episodic future thought, or episodic counterfactual thought, and whether successful or unsuccessful - is a representation, representationalism provides a unified treatment of episodic hypothetical thought as a whole.

\subsection{The Silence of Episodic Hypothetical Thought}

Though it therefore has considerable appeal, indirect realism faces a serious problem. It is the role that it assigns to satisfaction conditions that allows representationalism to provide a unified account of episodic hypothetical thought as a whole. But it is also this role that gets representationalism into trouble, for there is good reason to think that episodic hypothetical thoughts do not in fact establish their own satisfaction conditions.

We build here on Travis (2004) argument for the view that perceptual states are "silent" with respect to their capacity to establish satisfaction conditions. As Travis argues, perceptual states cannot be assessed for accuracy alone because there is more than one state of affairs that will satisfy how things appear to the subject. The satisfaction conditions are determined, instead, by things that are external to perceptual states, such as the subject's doxastic states. ${ }^{4}$ Consider a pair of scenarios. In the first, you see an apple in the kitchen and decide to eat it, only to discover that it is a wax apple. In the second scenario, you see an apple in the kitchen but decide not to eat it, because you know that it is one of the wax fruits your partner bought last week. The visual experiences at issue in these two scenarios may appear exactly alike to you, but their satisfaction conditions are arguably different: the former experience is about a real apple, while the latter is about a fake apple. Because how the experiences appear to you is the same while the satisfaction conditions are different, we may conclude that satisfaction conditions are determined by something external to perception - in this case, your beliefs.

Episodic hypothetical thought, we suggest, is similarly silent. Silence here refers, in particular, to the capacity of the mental state to determine the temporal location (past/future) and modal status (actual/possible) of the event. Consider another pair of scenarios. In the first, you have an episodic hypothetical thought that we would intuitively describe as a memory of your tenth birthday party. It seems clear to you that you are remembering an event that occurred in the actual past and not merely imagining a possible future event. This seems clear to you because you have a set of beliefs that suggest it. You believe, for instance, that you are currently an adult, that the child presented in the thought is a younger version of you, and that human development is an irreversible process that goes from childhood to adulthood. What we suggest is that it is these and other relevant beliefs that determine that your thought is about an actual past event. Compare this first scenario to a second, in which you wake up one morning with an unusual set of mistaken beliefs. You believe, for example, that

\footnotetext{
${ }^{4}$ Travis himself does not explicitly endorse a doxastic account, but this has been one important development of his argument (see, e.g., Antony 2011; Genone 2014).
} 
humans are born adults and become children only later in their lives. Now, suppose that you have the same episodic hypothetical thought as in the first scenario. Due to your mistaken beliefs, the thought is now about a possible future event. Despite still believing that you are an adult and despite taking the person presented in the thought to be you, your belief about how human individuals develop has changed, thus changing the temporal reference of the thought. In general, the idea is that, if the same thought can refer either to the past or to the future depending on the beliefs that accompany it, episodic hypothetical thought must be silent with respect to temporal location and modal status.

Note that the suggestion is not that subjects must be consciously aware of the beliefs that accompany their episodic hypothetical thoughts and that determine the satisfaction conditions of the latter, for beliefs can influence thoughts both at the personal level, when the subject is or can be conscious of them, and at the subpersonal level, when the subject is not necessarily conscious of them. Thus, even if it seems to the subject, at the personal level, that there are no relevant beliefs that accompany his thought, it does not follow that these are not present at the subpersonal level. We come back to this point below.

The silence of episodic hypothetical thought challenges the representationalist approach to the co-reality problem and the problem of confabulation and misremembering. Consider the co-reality problem. The fact that the objects of episodic hypothetical thought are representations is no longer sufficient to an explanation of temporal reference and of its modal status, for these are now explained by the beliefs that accompany episodic hypothetical thoughts. Because, when considered alone, representations can be satisfied by past/future and actual/possible events equally, and because the reference to past or future and the modal status of events are established by things external to representations, such as the doxastic states, temporal reference and modal status cannot be internal features of representations. Consider the argument from confabulation and misremembering. Representationalism similarly has difficulty explaining confabulation and misremembering, for the fact that the objects of episodic hypothetical thought are representations is also no longer sufficient to an explanation of which particular event serves as the satisfaction condition for a given occurrence of episodic hypothetical thought. Because assessing the accuracy of a representation requires the identification of the particular event that is being assessed, and because such an identification requires the determination of temporal reference and modal status, a given episodic hypothetical thought is said to be an occurrence of misremembering or an occurrence of confabulating only in relation to the beliefs that accompany those thoughts.

This concludes the second part of the negative stage of our argument. To summarize: The core claim of this section is that episodic hypothetical thoughts are silent with respect to the temporal locations and modal statuses of the relevant events. It is not episodic hypothetical thoughts themselves but rather the beliefs that accompany them that determine those features. If correct, the "silence argument" undermines the motivation for adopting representationalism. We conclude that representationalism, like direct realism, no longer appears to be a viable option. 


\section{The Pragmatist Alternative}

This brings the first, negative stage of our argument to a close. If our reasoning in Sections 2 and 3 is on the right track, neither direct realism nor representationalism can provide a viable account of the objects of episodic hypothetical thought. An alternative to both accounts is thus required. The purpose of the second, positive stage of our argument is to develop such an alternative.

The alternative that we propose draws inspiration from classical pragmatism. An important aim of pragmatism has always been to overcome dichotomies created by classical philosophical systems. Among these dichotomies are the opposition between mind and body (see Dewey 1958; McDowell 1996; Godfrey-Smith 1998, 2010) and the dispute between direct and indirect theories of perception (see Haack 1994; Bergman 2007; Legg 2014; Wilson 2016). The latter was of particular interest to Peirce, and, while he did not himself address the topic of episodic hypothetical thought, Peirce's attempts to bridge direct and indirect theories of perception within a pragmatist framework suggests that pragmatism may contain insights relevant to the question of the objects of episodic hypothetical thought. Our strategy in the remainder of the paper will thus be to focus on one central Peircian idea, using it as a starting point for answering that question. This idea is the pragmatic maxim, Peirce's claim that the meanings of concepts should be analyzed in terms of the conceivable practical effects that their referents have or would have. For example, the concept HARD, which Peirce defined as that which would not be scratched by many other things, is understood in terms of the effects hard things would have if we were to interact with them. We begin (Section 4.1) by motivating pragmatism. We then develop (Section 4.2) a pragmatist account of the objects of episodic hypothetical thought, showing how the account handles temporal reference and distinguishes among different kinds of episodic hypothetical thought in a manner consistent with the silence of episodic hypothetical thought as described in Section 3. Finally, we show (Section 4.3) how the pragmatist account deals with the problems raised in Section 2 - the co-reality problem and the problem of confabulation and misremembering - thereby avoiding disjunctivism.

Before proceeding, we acknowledge, again, that readers unfamiliar with pragmatism may find our account to be outlandish in certain respects. We ask such readers to bear with us, suspending judgement until they have seen what pragmatism allows us to say about the objects of episodic hypothetical thought. Moreover, we emphasize, again, that the arguments for the negative conclusions given in Sections 2 and 3 does not rest on pragmatist assumptions. Readers unpersuaded by our positive argument in Section 4 are thus free to accept our negative arguments and to develop nonpragmatist alternatives to our account.

\subsection{Motivating Pragmatism}

We begin with some terminology. By "pragmatic objects", we will mean objects of mental states that are immediately available to the mind, regardless of whether they exist. Objects such as tables and unicorns are pragmatic objects, because they are immediately available to us in thought, perception, memory, and so on. But things 
that we do not usually think of as "objects" can also qualify as pragmatic objects: mental states, such as a pain, and physical events, such as the World Cup final, can be the objects of our mental states - e.g., one can hope that one's pain goes away or wish to attend the World Cup final. Pragmatic objects thus resemble intentional objects, as originally introduced by Brentano (1973), in the sense that they are the things that mental states are directed at. However, while Brentano took intentionality to be what distinguishes the mental from the physical, the pragmatist account defended here will treat pragmatic objects as ontologically neutral.

Pragmatic objects are also distinguished from intentional objects by the fact that they are always seen as objects for action; they are, that is, conceived of in relation to how they prompt, or would prompt, subjects to act in virtue of being related to them. By "actions", we will mean both physical actions and mental actions resulting from the relation between a subject and a pragmatic object. For example, picking up a stone on the beach as a souvenir counts as a physical action because the pragmatic object (the stone) prompts certain bodily movements. Similarly, thinking of the stone as a good souvenir counts as a mental action because the pragmatic object (the stone) prompts the occurrence of a certain mental state. (It is, of course, also possible for pragmatic objects to cause physical actions and mental actions at the same time, such as when one forms the belief that the stone would be a good souvenir and therefore moves one's body to pick it up.)

Because pragmatic objects are identified at the phenomenological level, they are defined in ontologically neutral terms: they are objects of the mind that prompt action, meaning that they might or might not exist and might or might not be physical or material. The strategy employed here is thus similar to the phenomenological reduction proposed by Husserl $(1982,1988)$. In order to identify pragmatic objects, we suspend our previous knowledge of the world and focus solely on what is immediately present to the mind (see Gallagher and Zahavi 2013, 24). For example, when one hallucinates a dog, one's hallucinatory experience has a pragmatic object because it prompts one to act. However, when we consider this pragmatic object in relation to other things that we know about the world, we might infer that it does not exist concretely, because it is not the kind of thing that would be perceived by other subjects in the same situation.

The ontological neutrality of pragmatic objects raises a question: how can we distinguish between existent pragmatic objects, such as chairs and stones, and nonexistent pragmatic objects, such as possible objects and possible events? This is where the pragmatic maxim comes into play. The maxim says that the meaning of a concept is determined by the practical effects that it would have in experience. In line with the maxim, we propose to distinguish between existent and non-existent pragmatic objects in terms of the practical effects these would have in experience. The idea is that pragmatic objects prompt actions, which, when they enable subjects to deal successfully with their environments, become habitual. For example, driving a car for the first time is a complex task that requires constant attention. Inexperienced drivers find it challenging to change gears, but, as they get used to driving, this becomes an automatic task. Through repeating the same actions to deal with the same complex task, drivers develop what we will call a "habit of action", which is the ability to reproduce, in current situations, actions that enabled them to deal successfully 
with earlier similar situations. We can distinguish between two kinds of habits of action. "Teleological" habits of action are developed over the course of an individual's life to achieve goals that are relevant to the individual - for example, driving. "Teleonomic" habits of action are evolved and consequently shared among individuals of the species - for example, the tendency of the squid to release ink when approached by a predator. This distinction enables us to distinguish between existent and non-existent pragmatic objects, for these differ with respect to the kind of habits of action that they recruit.

Consider the visual experience of seeing a dog in a lab. This experience will prompt certain actions. Suppose that you are surprised to see the dog and ask your colleagues why it is standing there. They tell you that there is no dog in the lab and that you must be hallucinating. In this case, you perceive a pragmatic object, but the actions generated by the object fail to be coordinated with the actions of your colleagues in that situation. In other words, the effects generated by the pragmatic object of your experience are different from the effects generated by the pragmatic objects of your colleagues' experiences. Thus, despite the fact that your experience has a pragmatic object, the object of your experience does not exist in the sense that it fails to generate the practical effects that would coordinate your experience with the experiences of your colleagues. On our account, the difference between existent and non-existent objects is one of degree and not one of kind. The difference of degree is explained in terms of the kinds of habits of action that are recruited by an object. A pragmatic object exists if it recruits teleonomic habits of action in multiple subjects, thus allowing for the coordination of actions in meaningful ways among those subjects. For example, to complete a puzzle, humans can coordinate their actions with each other in meaningful ways because they can identify shape and color in similar ways, which is only possible because they share certain evolved perceptual capacities. In contrast, a pragmatic object is non-existent when it recruits only teleological habits of action, which usually do not allow for intersubjective coordination of actions. For example, a thought of a tenth birthday party will recruit different habits of action in different individuals, as those habits will depend on how each individual interacted with birthday parties in the past. We thus avoid using ontological notions, such as "physical" and "mental", to distinguish between existing and nonexisting things. This makes explicit a crucial commitment of the pragmatist account, which is that, because the objects of different mental states are all pragmatic objects, they are all fundamentally of the same kind. This commitment is crucial because, as we will see, it allows us to say that the relationship of mental states to existing and non-existing objects is of the same kind, which is an important step towards avoiding disjunctivism.

The motivation that we have offered here for our account of pragmatic objects as the objects of thought may strike some as insufficient. Supplying a fuller motivation for the account would require spelling out the particular version of pragmatism underlying it in more detail. But our intention here is not to provide a general argument for pragmatism but, more modestly, to show that a broadly pragmatist view can provide useful insights into the relationship between the mind and its objects. What the pragmatist account offers is a triadic understanding of mental relations, in which a mental relation is viewed as being irreducibly constituted by, first, a mental 
state, second, its pragmatic object, and third, the actions prompted by their interaction. This "triadic view" offers an alternative to two-place or dyadic view of mental relations (see Rowlands 2015), according to which they are constituted solely by how mental states stand with respect to their objects. The key novelty introduced by the triadic view, in contrast to the dyadic views which are implicitly assumed by both representationalism and relationalism, is that it gives actions a constitutive role in the determination of mental relations. In doing so, it offers a new perspective on the problems for relationalism and representationalism outlined in Sections 2 and 3.

We apply the pragmatist framework to these problems in the remainder of Section 4. Our plan of attack is the following. In Section 4.2, we propose an account of the temporal reference of episodic hypothetical thought and of the actuality or possibility of its objects in terms of the habits of action that are recruited by pragmatic objects. We build on this account to address the problems raised above for direct and indirect realism, considering, first, the problem of confabulation and misremembering and, second, the co-reality problem. With respect to the former, we employ the notion of habits of action to argue that confabulation and misremembering can be distinguished based on the inferences that subjects make when they are related to pragmatic objects. With respect to the latter, we rely on the characterization of pragmatic objects as ontologically neutral to argue that their existence (or non-existence) is determined only in relation to the actions that they prompt in subjects. In Section 4.3, we conclude that the account therefore has the potential to avoid extreme disjunctivism.

\subsection{Applying Pragmatism}

We begin with the temporal reference of episodic hypothetical thought. We then consider the actuality/possibility of its objects.

\subsubsection{Temporal Reference}

As suggested above, the temporal reference of an episodic hypothetical thought its reference to the past or the future - depends on the habits of judging that are recruited by its pragmatic objects. A habit of judging is constituted when subjects interact with pragmatic objects and form beliefs about those objects. For example, when eating an apple for the first time, a subject might satiate his hunger and have a pleasant experience, which will lead to the formation of judgments about apples, such as "apples are nutritious" and "apples are tasty". These judgments will then serve as guides for action in future interactions with apples. If faced with an apple again, the subject will be inclined to perform certain actions (e.g., eat the apple) rather than others (e.g., throw it away). In short, habits of judging are beliefs that influence the subject to act in a certain way based on the outcome of previous experiences. Note that, although one is often aware of some of the beliefs that influence one's actions, our account is compatible with the possibility that many habits of judging influence thoughts sub-personally, i.e., without one's being aware of their presence.

On the pragmatist account, episodic hypothetical thought establishes temporal reference in virtue of habits of judging of this sort. To illustrate, suppose that you are 
thinking about how your life will be in ten years. The pragmatic object of your thought is an event in which there is a person who looks reasonably like you, is ten years older than you are, and lives in a beach house. Despite individuating a state of affairs, the pragmatic object does not establish a particular temporal reference. The reference to the future established by the thought is due rather to the habits of judging that accompany it. For instance, the beliefs that the person in question looks reasonably like you, that you are not currently that old, and that situations in which you are older or where you have a beach house are still to come, allow you to infer that the thought is about a possible event in the future. The same goes for thoughts about the past. Suppose that you are thinking about your tenth birthday party. The pragmatic object of your thought is an event in which there is a child who looks you when you were ten. Again, despite individuating a state of affairs, this pragmatic object does not by itself establish a particular temporal reference. The reference to the past established by this thought is due to the habits of judging that accompany it. For instance, the beliefs that the individual in question is you, that you are no longer ten, and that situations in which you are younger have already happened or are no longer possible allow you to infer that the thought is about the past.

An obvious objection to this account of temporal reference is that it is inconsistent with the phenomenology of episodic hypothetical thought. When we think about past or future events, we do not usually engage in higher-order cognitive processes in order to form judgments about their temporal locations. In most cases, it seems to one that those thoughts simply present themselves to one as being about the past or the future. We discus this object in detail in Section 5, where we argue that the fact that temporal reference is sometimes built into the phenomenology of episodic hypothetical thought is therefore not incompatible with the claim that it is underwritten by habits of judging.

\subsubsection{Varieties of Episodic Hypothetical Thought}

With an account of temporal reference in place, we turn to modal status. On the pragmatist account, episodic hypothetical thoughts differs with respect to two kinds of habits of action recruited by their pragmatic objects. The first is responsible for presenting objects as being located in the past or future. We have just discussed habits of this kind. The second is responsible for presenting objects as being actual or merely possible. We now discuss habits of this kind, showing how the two kinds of habit in conjunction enable us to distinguish among different kinds of episodic hypothetical thought.

An episodic hypothetical thought is an episodic memory when its pragmatic object recruits habits of judging that place it in the past and habits of action that prompt the subject to act as if the object has been the case before. To illustrate, consider a first scenario. Some years ago, John decided to save five percent of his salary to attend a music festival that happens every year. In 2018 (the present), John remembers going to the 2017 festival. The pragmatic object of John's thought is an event involving an individual who looks reasonably like him going to the 2017 festival. John takes this thought to be about the past because he believes, for example, that the thought is about himself and that situations where he is younger are in the past. Moreover, 
because the pragmatic object makes John react to the thought in a certain way e.g., he feels nostalgic about the festival and thinks it was a good idea to have saved money to attend it - the object is presented to him as being actual, i.e., as being something that happened before.

Similarly, an episodic hypothetical thought is a (past-oriented) episodic counterfactual thought when its pragmatic object recruits habits of judging that place it in the past and habits of action that prompt the subject to act as if the object was once, but no longer is, possible. To illustrate, consider a second scenario. In 2018, John thinks about how the 2017 festival would have been if it had not been definitively cancelled in 2016. The pragmatic object of his thought is an event involving an individual who looks reasonably like him in a festival occurring in 2017. John takes this thought to be about the past because he believes, for example, that the thought is about himself and that situations where he is younger are in the past. Moreover, because the pragmatic object makes John react to the thought in a certain way, e.g., he does not feel nostalgic and he is not disposed to save part of his salary, the object is presented to him as having been once possible, but not as being possible at the moment of his thought.

An episodic hypothetical thought is an episodic future thought when its pragmatic object recruits habits of judging that place it in the future and habits of action that prompt the subject to act as if the object is possible. This is illustrated in a third scenario. In 2018, John thinks about how the 2019 edition of the festival will be. In this scenario, the festival was not cancelled in 2016. The pragmatic object of John's thought is the event describing an individual who looks reasonably like him going to the 2019 festival. John takes this thought to be about the future because he believes, for example, that 2018 is the present year and that 2019 will follow it. Moreover, because the pragmatic object makes John react to the thought in a certain way, e.g., he will continue to save his salary every month to attend the 2018 edition and look forward to the festival, the object is presented to him as being possible.

Finally, an episodic hypothetical thought is a future-oriented episodic counterfactual thought when its pragmatic object recruits habits of judging that place it in the future and habits of action that prompt the subject to act as if the object was once, but no longer is, possible. ${ }^{5}$ Note that future-oriented episodic counterfactual thought differs from past-oriented episodic counterfactual thought only in its temporal reference. Both are thoughts about things that were possible at a given moment but are no longer possible at the moment of thinking. This is illustrated by a fourth scenario. In 2018, John thinks about how the 2019 edition of the festival would have been if it had not been cancelled in 2016. The pragmatic object of John's thought is the event describing an individual who looks reasonably like him going to the 2019 festival. John takes this thought to be about the future because he believes, for example, that 2018 is the present year and that 2019 will follow it. Moreover, because the pragmatic object makes John react to the thought in a certain way, e.g., he will not be disposed to save his salary to go to the 2019 edition, the object is presented to him as having been once possible, but not as being possible at the moment of his thought.

\footnotetext{
${ }^{5}$ Episodic future thought and future-oriented episodic counterfactual thought are not normally distinguished from each other; one virtue of the pragmatist account is that it makes clear the importance of drawing this distinction.
} 
In short, while the particular habits of action recruited will vary from situation to situation, it is the presence of habits of action establishing temporal reference and habits of action marking objects as actual, possible, or not possible, that determine the nature of an episodic hypothetical thought.

One may worry that this account rules out the possibility of entertaining multiple thoughts about the same event. ${ }^{6}$ Suppose that, on several different occasions, you entertain thoughts about your tenth birthday party. Suppose further that the pragmatic object of one thought describes your friends and family as being there and you as having chocolate cake and that the pragmatic object of another thought describes your friend and family as being there but does not describe you as having chocolate cake. If the pragmatist account is right, one may worry, these two thoughts cannot in fact both be about your tenth birthday party, since their pragmatic objects have different features. The worry, in general, is that, given that there is significant variation in how we think about events over time, the pragmatist account implies that we can never think about the same event twice.

In response to this worry, we invoke the characterization, offered in Section 4.1, of pragmatic objects as being identified at the phenomenological level. Because they are identified at this level, they are silent in the sense that they are not themselves about events in the world; reference to events, instead, obtains in virtue of the actions prompted by pragmatic objects. This means that, even if two thoughts have different pragmatic objects, as in the example above, it does not follow that they are about different events. This would follow given a dyadic view on which the features of the objects themselves would be responsible for establishing reference, but it does not follow given the triadic view. On the pragmatist account, while some similarity in terms of the phenomenological features possessed by their pragmatic objects is required in order for two thoughts to refer to the same event, that similarity alone does not determine coreference. In view of the scope of our discussion here, we have focused on how habits of action — including habits of judging — establish temporal reference and actuality/possibility. But reference is also to be explained in terms of such habits. Consider again the example above. Despite the fact that the relevant pragmatic objects have different phenomenological features - the first describes you as having chocolate cake but the second does not - both thoughts may refer to the same event if they involve not only habits that place the event in the past and lead you to act as if it were actual but also, in consequence, habits that lead you to form the belief that the relevant event is the particular event of your tenth birthday party. Two thoughts will thus count as being about the same event as long as their pragmatic objects share some - but not necessarily all — phenomenological features, there are habits establishing the same temporal reference and modal status, and there are habits leading the subject to believe that the pragmatic objects refer to the same particular event. The issue of how episodic hypothetical thoughts refer to particular events is a complex one, and addressing it in greater detail is beyond the scope of this paper. We hope, however, that these considerations suffice to show that the pragmatist account is capable in principle of addressing it.

\footnotetext{
${ }^{6} \mathrm{We}$ are grateful to an anonymous referee for raising this issue.
} 


\subsection{Avoiding Disjunctivism}

We have argued that different forms of episodic hypothetical thought can be distinguished in terms of temporal location and modal status, where these are determined by the habits of action that are recruited by their pragmatic objects. The problem of confabulation and misremembering, the co-reality problem, and the issue of disjunctivism remain to be addressed. Addressing these questions will occupy us for the remainder of Section 4.3.

\subsubsection{The Problem of Confabulation and Misremembering}

Before we discuss the pragmatist approach to confabulation and misremembering, let us be more precise about what we mean by "remembering", "misremembering", and "confabulation". We will say that a mental state is a case of remembering if it allows for true inferences (i.e., inferences to true conclusions) and no false inferences (inferences to false conclusions) about the past; it is a case of misremembering if it allows for some true and some false inferences about the past; and it is a case of confabulation if it allows only for false inferences about the past. However, since genuine occurrences of remembering can involve inaccurate elements (see, e.g., De Brigard 2014a), this distinction applies only in relation to particular contexts. To illustrate, suppose that a subject is trying to remember how the weather was during his tenth birthday party. If he remembers that the party was on a sunny day, and if that happens to be true, he is remembering the event accurately even if he remembers playing with his friend John, when it is false that John attended the party. Depending on whether we evaluate the mental state in relation to the weather or to John's attendance to the party, the assessment of it as true or false will vary. For this reason, we will say that a putative memory is evaluated in the "context of thought" in which it occurs, where a context of thought refers simply to the context specifying the elements relevant to assessing the accuracy of the inferences made by subjects.

With these clarifications in place, the pragmatist account says that a given mental state is an occurrence of remembering, misremembering, or confabulation depending on the nature of the inferences that are prompted by its pragmatic object in contexts of thought. The pragmatic object of a state of remembering prompts only true inferences about the past; the pragmatic object of a state of misremembering prompts some true and some false inferences about the past; and finally, the pragmatic object of a state of confabulating prompts only false inferences about the past. These definitions are compatible with the silence argument presented in Section 3 and with the triadic view, since it is the actions - in this case, the inferences - generated by the interaction between a mental state and a pragmatic object that explain the differences between kinds of episodic hypothetical thought.

Consider, first, remembering. When one remembers something, one thinks about an event to which one was once related in perception. The objects of perception, in turn, are themselves pragmatic objects and recruit habits of action. For example, when you see a yellow chair, you form the perceptual judgment "the chair is yellow" because the habits of judging that are recruited are the habits to judge objects with such-and-such properties as chairs and objects of that color as yellow. If these habits 
allow you to make true inferences about your environment, then your experience is said to be veridical. If they do not, then it is said to be non-veridical. In parallel to this account of the veridicality of perception, the pragmatist account says that a mental state is an occurrence of remembering when, in a given context of thought, the pragmatic object recruits habits of judging that allow the subject to make true inferences about the past. A "true inference about the past" is, in turn, one that would be true of the perception of the event. For example, in the birthday case above, the subject remembers correctly that it was a sunny day because the inferences he makes on the basis of this thought would also be true of the perception of the event. Note that we are not saying that the subject needs to be able to perceive the event again but only that, if this were possible, the inferences generated by remembering would be true of his perception of the event. Similarly, we are not claiming that successful remembering must allow the subject to make all the true inferences that perception of the event would enable him to make but only that it must allow him to make those that are relevant in the context of thought.

Consider, second, misremembering. In contrast to remembering, a mental state is an occurrence of misremembering when, in a given context of thought, the pragmatic object recruits habits of judging that allow for some true and some false inferences about the past, i.e., some inferences that would be true and some inferences that would be false of the perception of the event. In the birthday case, the subject misremembers because the pragmatic object of his thought allows for both true inferences (that it was a sunny day) and false inferences (that he played with John). Consider, finally, confabulation. A mental state is an occurrence of confabulation when, in a given context of thought, the pragmatic object recruits habits of judging that allow only for false inferences about the past, or inferences that would be false of the perception of the event. In the birthday case, the subject confabulates when, in the relevant context of thought, he judges mistakenly that he played with John because this inference would be false of the perception of the event.

Two points need to be emphasized here. The first is that the account does not require that the inferences made on the basis of remembering should have been made at the time of perceiving. For example, the subject above need not have formed the perceptual judgment "it is a sunny day" during his tenth birthday party for the thought to count as remembering. The relationship here is counterfactual, that is, the inference made on the basis of remembering is true if perception of the event would have yielded a similar perceptual judgment that would be true. So, this account does not require an actual but only a counterfactual correspondence between inferences made on the basis of remembering and perceptual judgments.

The second point is that the pragmatist account does not require that the habits of action recruited in remembering match the habits of action recruited in perception. Because perception and memory ultimately relate to pragmatic objects, if such a match were required, there would be no distinction between remembering something and perceiving something. The account only requires that the truth-value of the inferences made on the basis of remembering in a context of thought and the inferences that would have been made on the basis of a perception of the event be the same. This highlights an important difference between the pragmatist account and causal theories of remembering (e.g., Martin and Deutscher 1966; see Debus 2017 
for discussion). On the pragmatist account, genuinely remembering an event does not require the preservation of a trace connecting the actual memory to a previous perceptual state (see De Brigard 2014b; Robins 2017 for discussion). The subject must have perceived the event at some point in his life, but the connection between remembering and perceiving is established in counterfactual terms, i.e., in terms of whether the inferences generated by remembering would be true of the past perception of the event.

One might worry that the fact that it does not require the presence of a trace connecting remembering to a past perceptual experience renders the account unable to distinguish cases of remembering from cases of veridical confabulation (see Michaelian 2016b; Bernecker 2017). A veridical confabulation is a mental state such that its pragmatic object recruits habits of action that allows for true inferences of the past but such that the subject has never been perceptually related to the relevant event. In other words, the subject makes the right kind of inferences only accidentally. For example, a subject can confabulate being at the 2002 World Cup Final and only accidentally make true inferences about the match, such as that Ronaldo scored two goals for Brazil, when in fact the subject did not go to the stadium. The pragmatic object here prompts true inferences, but these might be due to sheer guessing. So, this is a confabulatory state that only accidentally happens to be veridical.

Veridical confabulation would pose a problem for the pragmatist account only if it held that a subject can remember an event even if he did not perceive it in the past. But this is not what the account holds. Instead, it holds that we are to look at the inferences generated by remembering and consider whether those inferences would be true of the subject's perception of the event. In the case above, the mental state would count as a case of veridical confabulation rather than a case of genuine remembering because the inferences generated by the confabulation would not be true of any of the subject's past perceptual states. One might reply, however, that there could be cases of veridical confabulation in which the subject makes true inferences based on a past perceptual state. For example, by seeing Ronaldo score two goals on television, and not at the stadium, when the subject says that he saw Ronaldo score two goals at the final, he is making a true inference about the past based on a previous perceptual state, namely, watching the 2002 Final on television. This would mean, the reply continues, that the subject is remembering and not confabulating. In response, we point out that the reply rests on an ambiguity relating to the kind of inference the subject is making when he says that he saw Ronaldo scoring two goals. In the initial case described, the subject infers that he saw Ronaldo scoring from the stadium, but this is not the same thing as seeing Ronaldo scoring from the television. So, the inference he is making on the basis of his confabulation would not be true of any past perceptual state because it is not the case that he saw Ronaldo scoring from the stadium.

\subsubsection{The Co-reality Problem}

With the problem of confabulation and misremembering out of the way, we turn to the co-reality problem. The challenge is to explain how events that no longer exist might be constituents of mental states. Our account appeals here to the neutrality of 
pragmatic objects and the triadic view discussed above. The neutrality of pragmatic objects, again, refers to the fact that they are only said to be existent or non-existent, to be in the past or in the future, in relation to the habits of action that they recruit. Building on this, the triadic view says that the nature of a mental relation is irreducibly triadic, in that it can only be determined by looking (first) at the actions generated by the interaction between (second) a mental state and (third) a pragmatic object.

By treating the objects of episodic hypothetical thought as pragmatic objects, the pragmatist account avoids the co-reality problem. Because existence is understood in terms of the actions generated by the interaction between a mental state and a pragmatic object, instead of as a property ascribed to the objects of episodic hypothetical thought, the pragmatist account is not committed to the idea that non-existent things are constitutive parts of episodic hypothetical thought. So, for example, when a subject thinks about how his graduation would have been if he had attended another university, the pragmatic object describing this event is a constitutive part of his thought, but what determines whether his thought is about an existing or non-existing event is not an intrinsic feature of the pragmatic object but rather the actions generated by it. This account avoids problems pertaining to the ontological status of those objects while simultaneously preserving the distinction between existence and nonexistence, which are now understood in relation to habits of action. By the same token, the co-temporality problem, too, is avoided, for pragmatic objects need not be located in the past/future in order for them to be about the past/future. Temporal reference, as we argued above, is established by habits of action. In this respect, the pragmatist account offers an alternative to the eternalism (Bernecker 2008) discussed in Section 2, for it does not require us to say that past events continue to exist in the present.

A worry that arises at this point is that pragmatism is just a form of representationalism in disguise because, one might say, "pragmatic object" is just a new term for the old idea of a representation. For two reasons, this worry is unfounded. First, because pragmatic objects are silent in Travis (2004) sense, they do not establish their own satisfaction conditions. As discussed in Section 4.1, pragmatic objects establish reference only in the context of the actions they prompt in subjects. So, unlike representations, which do establish their own satisfaction conditions, pragmatic objects are silent. Second, traditional representationalist views are based on discontinuist views of mind and world (see Menary 2009). In contrast, the pragmatist account incorporates a continuist view, on which the objects of the mind (so-called "representations") and the objects of the world (so-called "physical things/events") are viewed as being fundamentally the same. In line with the pragmatic maxim introduced earlier, the difference between them is accounted for in terms of the effects they generate in experience. Thus, "pragmatic object" is not just a new term for the old idea of a representation, as pragmatic objects are incompatible with at least two important ideas associated with representations.

\subsubsection{Disjunctivism Avoided}

We are aware that the account developed in the preceding sections presupposes claims that many readers will be inclined to reject. Our primary aim, however, is not 
so much to develop a definitive answer to the question of the objects of episodic hypothetical thought as it is to provide an initial discussion that might serve to set the stage for future work on the question. Thus, we invite readers unprepared to sign on to the full-blown pragmatist account to take a more modest point away from our discussion: even if the details of the pragmatist account turn out to be wrong, the suggestion that a proper understanding of the nature of the objects of episodic hypothetical thought requires moving away from a narrow focus on the nature of mental states and their objects to a broader focus including elements external to this dyad, such as the actions or beliefs generated by their interactions, might be right. Nevertheless, the merits of the pragmatist approach should not be underestimated, and, in the remainder of this section, we show how the approach enables us to avoid disjunctivism.

Disjunctivism poses a problem because it postulates a fundamental discontinuity between remembering and other forms of episodic hypothetical thought (Debus 2014; Perrin 2016). This discontinuity, as we saw above, forces the relationalist to adopt problematic commitments in order to save his view. The pragmatist account, in contrast, offers a framework in which the continuity between remembering and other forms of episodic hypothetical thought is preserved, thus offering relationalists an option that does not require disjunctivism. ${ }^{7}$

The discontinuity between remembering and other forms of episodic hypothetical thought postulated by disjunctivists is grounded in the view that the objects of remembering exist but the objects of other forms of episodic hypothetical thought do not. As Debus $(2008,2014)$ argues, remembering involves being in an experiential relation to events which cannot possibly obtain in other forms of episodic hypothetical thought. In opposition to this view, the pragmatist account denies that remembering is distinctive because of the existence of such an experiential relation. Instead, the difference between remembering and other forms of episodic hypothetical thought is explained in terms of the habits of action recruited by their pragmatic objects. In contrast to disjunctivism, this account relies not on intrinsic features of the objects, such as whether they exist, but rather on the actions generated by them. Thus, because the pragmatist account focuses on action, even if we grant Debus's claim that remembering involves a kind of experiential relation that other forms of episodic hypothetical thought lack, it does not follow that we are dealing here with two fundamentally distinct kinds of mental states. This makes it possible to say, in turn, that all occurrences of episodic hypothetical thought relate to the same kind of thing — namely, pragmatic objects — which allows for an even stronger form of relationalism, one on which all occurrences of episodic hypothetical thought are relational.

A basic problem for the claim that all occurrences of episodic hypothetical thought are relational is that it is simply incoherent to say that we can be directly related to things that have ceased to exist or that never existed in the first place. This becomes a problem for the pragmatist account only if it is taken to incorporate a dyadic view of mental relations, which it does not. Dyadic views take mental relations to be twoplace relations composed by a mental state and an object, such that, if one of the

\footnotetext{
${ }^{7}$ For a similar proposal focusing on disjunctivism about perception, see Sant'Anna (2017).
} 
constituents is missing, the relation fails to obtain. So, because the objects of forms of episodic hypothetical thought other than episodic memory are viewed as non-existent objects, it is not possible for episodic hypothetical thought to relate to those objects. This view assumes, however, that the predicates "existent" and "non-existent" apply to objects prior to their being parts of mental relations. The pragmatist account denies this explicitly when it commits to a neutral characterization of pragmatic objects. By refraining from drawing the distinction by relying on ontological notions, "existence" and "non-existence" are applied to objects when they are considered as parts of irreducibly triadic relations; more specifically, those predicates are applied to objects in relation to the actions generated by the interaction between a mental state and a pragmatic object. Thus, because the pragmatist account commits to a triadic view of mental relations, it does not require that episodic hypothetical thought relate to non-existent things in the sense implied by dyadic views.

It is important to note that pragmatic objects do not occupy a third and exclusive ontological category. The pragmatist account accepts the idea that things either exist or not, but it contests the possibility of drawing this distinction without taking into account our interactions with them. In a pragmatist spirit, we do not deny the importance of the distinction, but we do question the traditional use of ontological notions to frame it. The general motivation here lies in the conviction, shared by different pragmatist views, that reality is continuous and that, due to its continuity, the differences between things must be accounted for in a similarly continuous way.

This concludes the positive stage of our argument. To summarize: We have shown, in response to the problem of confabulation and misremembering, how a given occurrence of episodic hypothetical thought can be characterized as an instance of remembering, misremembering, or confabulation by considering whether its pragmatic object prompts wholly true, partly true/partly false, or wholly false inferences. We have shown, in response to the co-reality problem, how the triadic view and the pragmatist understanding of the existence and nonexistence of pragmatic objects allows us to avoid the idea that nonexistent things are constituents of episodic hypothetical thoughts. And we have shown, finally, how these features of the pragmatic approach enable it to avoid extreme disjunctivism. In doing so, the pragmatic approach offers an unconventional, but stronger version of relationalism, where all forms of episodic hypothetical thought are relational. This new relationalist account has the advantage that it avoids the problems raised to the more traditional versions of the relationalism — more specifically, direct realism - while preserving desirable features of representationalism, namely, the idea that all forms of episodic hypothetical thought are occurrences of the same kind.

\section{Pragmatism and Autonoesis}

With this, our main argument is at a close. The negative stage of the argument (Sections 2 and 3) is meant to demonstrate that neither direct realism nor representationalism offers an adequate account of the objects of episodic hypothetical thought. The positive stage of the argument (Section 4) is meant to demonstrate that the pragmatist approach represents a promising alternative. While we acknowledge that 
readers antecedently sceptical of pragmatism may not be persuaded by the positive stage of our argument, we reiterate that such readers may nevertheless be persuaded by the negative stage, which does not itself rest on pragmatist assumptions. We thus look forward to the development of nonpragmatist accounts of the objects of episodic hypothetical thought.

In the meantime, we offer, by way of conclusion, a response to (what we take to be) the most pressing objection to the pragmatist account. One might, as we have acknowledged, object to the account itself on the ground that the metaphysical status of the pragmatic objects that it posits is unclear. But one might also object to the argument by means of which we have motivated the account, and it is to an objection of this sort that we want to respond in this final section of the paper.

Our overall argument for the pragmatist account depends on the argument for the silence of episodic hypothetical thought developed in Section 3. The key element of that argument is the claim that there is nothing internal to episodic hypothetical thoughts that suffices to establish satisfaction conditions for them. The objection to this claim is simply that, while perception may indeed be silent in Travis's sense, episodic hypothetical thought is not, for it has an autonoetic character. The view that episodic hypothetical thought — or at least episodic memory — has such a character has been particularly prominent in recent years (e.g., Mahr and Csibra 2017), but it has long been standard in both philosophy and psychology. James, for example, argued that memory involves a "feeling of the past direction of time" (James 1890, 650), while Russell saw memory as involving a "feeling of pastness" (Russell 1921, 161-162). Indeed, Klein (2015) has argued that this feeling — which has come, following Tulving (1985b) introduction of the term, to be known as autonoetic consciousness - has traditionally been taken to be definitive of episodic — as opposed to semantic - memory. In line with this tradition, Dokic, for example, has recently proposed an account on which episodic memory is characterized by an episodic feeling of knowing (Dokic 2014). Even those who are uneasy with the notion of a feeling of pastness typically simply relocate pastness from the phenomenology of episodic memory to its content. Fernández (2016), for example, characterizes the content of episodic memories as informing the subject that they originate in his past experience, and Martin (2001) and McCormack and Hoerl (1999) have defended similar views. Regardless of whether autonoesis is characterized in terms of phenomenology or in terms of content, its involvement in episodic memory suggests that episodic memories are not in fact silent. If this is right, then episodic memories, and perhaps episodic hypothetical thoughts of other kinds - Michaelian (2016c) has argued that episodic future thought involves a feeling of futurity analogous to the feeling of pastness - would, contra our argument, seem to be able to establish their own satisfaction conditions.

It is not clear, however, whether this objection poses a problem for our account, as there are reasons to think that subjects might have episodic memories that do not involve autonoesis. Klein and Nichols (2012) report the case of patient R.B., who, after an accident resulting in head trauma, could arguably remember events from his personal past without the sense of ownership that is usually ascribed to episodic memories. For example, in describing his recollection of studying with friends at MIT earlier in his life, R.B. claims that, besides seeing "the scene in [his] head" and 
being "able to re-live it", he has a "sense of being at there, at MIT, in the lounge" (Klein and Nichols 2012, 687). However, he adds, it does not feel like he owns the memory but rather like he is "imagining [or] re-living the experience [...] described by someone else" (687). As Klein and Nichols describe R.B.'s case, "he knows [the memories] are his in some sense, but he feels as though they are not 'owned'." (Klein and Nichols 2012, 688). On Klein and Nichols (2012) description, R.B. possesses information about the what, when, and where of the events in question and is also capable of "re-living" them. Moreover, he is able to recall them at will. The only thing missing is the sense of ownership of those memories. As he puts it, "I could answer any question about where I lived at different times in my life, who my friends were, where I went to school, activities I enjoyed, etc. But none of it was "me'." (Klein and Nichols 2012, 686). Thus, it seems that R.B.'s mental states resemble occurrences of episodic memory in normal subjects, except for the fact that they lack autonoesis. This suggests that, although autonoesis is pervasive in episodic memories in normal subjects, it is not a requirement for their occurrence. By mentioning R.B.'s case, we do not expect to adjucate the debate, but only to show that the claim that episodic memory necessarily involves autonoesis is not uncontroversial and, therefore, that autonoesis does not straightforwardly implies that the silence argument is wrong.

However, even if we set this issue aside and grant that episodic memory necessarily involves autonoesis, autonoesis can be incorporated into our view. Consider, first, phenomenological accounts. The fact that a memory seems to the subject to be about the past does not threat the pragmatist account. We have argued that beliefs can accompany episodic hypothetical thoughts in two ways, personally and subpersonally. While temporal reference can feature in the phenomenological character of a thought, which is defined in personal terms, it does not follow that what explains the occurrence of temporal reference must itself be a personal-level process. Thus, the claim that it seems to subjects that their thoughts are by themselves about the past is consistent with the claim that temporal reference is due to beliefs operating at the sub-personal level. This account parallels doxastic accounts of perceptual error, in which perceptual errors are viewed as a result not of perception but of the doxastic states accompanying it. On such views, subjects need not be conscious of the doxastic states that cause perceptual errors in the same way that, on our view, subjects need not be conscious of the doxastic states that determine temporal reference. Again, this is because doxastic states can operate at the sub-personal level. The upshot is that phenomenological features of our mental states including temporal reference or perceptual error can be consistently explained by sub-personal processes, which is compatible with the pragmatist account.

Consider, second, content-based accounts. On these accounts, it is possible for autonoesis to be built into the content of episodic hypothetical thought but not necessarily reflected in its phenomenology. Content-based accounts, we claim, are not incompatible with the pragmatist account. The pragmatist account denies that episodic hypothetical thought possesses content in isolation from other mental states, but it does not deny that it can have content when considered in relation to those mental states. Once we consider episodic hypothetical thoughts in relation to the beliefs that accompany them, they are no longer silent - i.e., they acquire content or 
satisfaction conditions. So, as long as the possession of satisfaction conditions, and therefore of temporal reference, is explained by this relation, the pragmatist account can accomodate the idea that episodic hypothetical thought can have content.

One final objection is that this response is inconsistent with the silence argument, the central claim of which is that episodic hypothetical thought is not representational and therefore not contentful. This apparent inconsistency can be resolved by noting that Travis's original silence argument does not rule out the possibility that perception may have content, in the sense of possessing satisfaction conditions, but only that perception itself can be assessed for accuracy. As long as we consider perception in relation to the things that ascribe satisfaction conditions to it, we can talk about it as being contentful. Analogously, the silence argument provided here does not rule out the possibility that episodic hypothetical thought may have content but only the possibility that episodic hypothetical thought itself can be assessed for accuracy. However, if we consider episodic hypothetical thought in relation to beliefs, nothing prevents it from acquiring content from those beliefs. Thus, the fact that the pragmatist account is compatible with content-based accounts of autonoesis is not inconsistent with the silence argument.

Acknowledgments We are grateful to the editor and to an anonymous referee for valuable suggestions made to a previous draft of the paper. We are also grateful to audiences at the University of Otago and the participants in the New Directions in the Philosophy of Memory workshop, also held at Otago, for helpful discussions on previous drafts of the paper. We'd also like to thank Ligia Coutes and Chloe Wall for comments on earlier drafts.

\section{References}

Antony, L. 2011. The openness of illusions. Philosophical Issues 21(1): 25-44.

Bartlett, F.C. 1932. Remembering: a study in experimental and social psychology. Cambridge: Cambridge University Press.

Bergman, M. 2007. Representationism and presentationism. Transactions of the Charles S Peirce Society 43(1): 53-89.

Bernecker, S. 2008. The metaphysics of memory. Berlin: Springer.

Bernecker, S. 2017. A causal theory of mnemonic confabulation. Frontiers in Psychology 8: 1207.

Brentano, F. 1973. Psychology from an empirical standpoint. Routledge. Transl. A. C. Rancurello and D. B. Terrell and L. McAlister.

Conway, M.A., and C. Loveday. 2015. Remembering, imagining, false memories \& personal meanings. Consciousness and Cognition 33: 574-581.

D'Argembeau, A., O. Renaud, and M. Van der Linden. 2011. Frequency, characteristics and functions of future-oriented thoughts in daily life. Applied Cognitive Psychology 25(1): 96-103.

De Brigard, F. 2014a. Is memory for remembering? recollection as a form of episodic hypothetical thinking. Synthese 191(2): 155-185.

De Brigard, F. 2014b. The nature of memory traces. Philosophy Compass 9(6): 402-414.

Debus, D. 2008. Experiencing the past: a relational account of recollective memory. Dialectica 62(4): 405-432.

Debus, D. 2014. Mental time travel': Remembering the past, imagining the future, and the particularity of events. Review of Philosophy and Psychology 5(3): 333-350.

Debus, D. 2017. Memory causation The routledge handbook of philosophy of memory. Routledge, eds. S. Bernecker, and K. Michaelian.

Dewey, J. 1958. Experience and nature. Courier Corporation.

Dokic, J. 2014. Feeling the past: a two-tiered account of episodic memory. Review of Philosophy and Psychology 5(3): 413-426. 
Fernández, J. 2016. Epistemic generation in memory. Philosophy and Phenomenological Research 92(3): $620-644$.

Gallagher, S., and D. Zahavi. 2013. The phenomenological mind. Routledge.

Gallo, D.A. 2010. False memories and fantastic beliefs: 15 years of the DRM illusion. Memory \& Cognition 38(7): 833-848.

Genone, J. 2014. Appearance and illusion. Mind 123(490): 339-376.

Godfrey-Smith, P. 1998. Complexity and the function of mind in nature. Cambridge: Cambridge University Press.

Godfrey-Smith, P. 2010. Dewey, continuity, and McDowell Naturalism and normativity, eds. D. MacArthur, and M. de Caro. Columbia: Columbia University Press.

Haack, S. 1994. How the critical common-sensist sees things. Histoire é,pistémologie langage 16(1): 9-34.

Husserl, E. 1982. Ideas Pertaining to a Pure Phenomenology and to a Phenomenological Philosophy First Book: General Introduction to a Pure Phenomenology. Nijhoff. Transl. F. Kersten.

Husserl, E. 1988. Cartesian Meditations. Kluwer. Transl. D. Cairns.

James, W. 1890. The principles of psychology. London: Macmillan \& Co.

Klein, S.B. 2015. What memory is. Wiley Interdisciplinary Reviews: Cognitive Science 6(1): 1-38.

Klein, S. B., and S. Nichols. 2012. Memory and the sense of personal identity. Mind 121(483): 677702 .

Laird, J. 1920. A study in realism. Cambridge: Cambridge University Press.

Legg, C. 2014. Things unreasonably compulsory: a Peircean challenge to a Humean theory of perception, particularly with respect to perceiving necessary truths. Cognitio 15(1): 89-112.

Loftus, E. F. 2005. Planting misinformation in the human mind: a 30-year investigation of the malleability of memory. Learning \& Memory 12(4): 361-366.

Mahr, J., and G. Csibra. 2017. Why do we remember? The communicative function of episodic memory. Behavioral and Brain Sciences. Online ahead of print.

Martin, M.G.F. 2001. Out of the past: episodic recall as retained acquaintance Time and memory: issues in philosophy and psychology, eds. C. Hoerl, and T. McCormack. Oxford: Oxford University Press.

Martin, C. B., and M. Deutscher. 1966. Remembering. Philosophical Review 75: 161-96.

McCormack, T., and C. Hoerl. 1999. Memory and temporal perspective: the role of temporal frameworks in memory development. Developmental Review 19(1): 154-182.

McDowell, J. 1996. Mind and world. Cambridge: Harvard University Press.

Menary, R. 2009. Intentionality, cognitive integration and the continuity thesis. Topoi 28(1): 31-43.

Michaelian, K. 2011. Generative memory. Philosophical Psychology 24(3): 323-342.

Michaelian, K. 2016a. Against discontinuism: mental time travel and our knowledge of past and future events Seeing the future: theoretical perspectives on future-oriented mental time travel, eds. K. Michaelian, S.B. Klein, and K.K. Szpunar. Oxford: Oxford University Press.

Michaelian, K. 2016b. Confabulating, misremembering, relearning: the simulation theory of memory and unsuccessful remembering. Frontiers in Psychology 7: 1857.

Michaelian, K. 2016c. Mental time travel: episodic memory and our knowledge of the personal past. Cambridge: MIT Press.

Newman, E.J., and D.S. Lindsay. 2009. False memories: what the hell are they for? Applied Cognitive Psychology 23(8): 1105-1121.

Perrin, D. 2016. Asymmetries in subjective time Seeing the future: theoretical perspectives on futureoriented mental time travel, eds. K. Michaelian, S.B. Klein, and K.K. Szpunar. Oxford: Oxford University Press.

Perrin, D., and S. Rousset. 2014. The episodicity of memory. Review of Philosophy and Psychology 5(3): 291-312.

Price, H.H. 1936. Memory-knowledge. Proceedings of the Aristotelian Society, Supplementary 15: 16-33.

Robins, S. 2017. Memory traces The routledge handbook of philosophy of memory. Routledge, eds. S. Bernecker, and K. Michaelian.

Robins, S.K. 2016. Misremembering. Philosophical Psychology 29(3): 432-447.

Rowlands, M. 2015. Arguing about representation. Synthese. Online ahead of print.

Russell, B. 1921. The Analysis of Mind. George Allen \& Unwin.

Russell, B. 1992. Human knowledge: its scope and limits. Routledge. Original publication.

Sant'Anna, A. 2017. Perception pragmatized: a pragmatic reconciliation of representationalism and relationalism. Philosophia. Online first. 
Travis, C. 2004. The silence of the senses. Mind 113(449): 57-94.

Tulving, E. 1985a. Elements of episodic memory. Oxford: Oxford University Press.

Tulving, E. 1985b. Memory and consciousness. Canadian Psychology/Psychologie Canadienne 26(1): $1-12$.

Wilson, A.B. 2016. Peirce's empiricism: its roots and its originality. Lexington Books. 